\title{
O GESTOR ESCOLAR E A INCLUSÃO DE ALUNOS PÚBLICO-ALVO DA EDU- CAÇÃO ESPECIAL MUNICIPAL
}

\section{THE SCHOOL MANAGER AND THE INCLUSION OF STUDENTS TARGET AUDIENCE OF MUNICIPAL EDUCATION}

\author{
iD Mara Rosane de Souza Soares \\ Mestre em Educação pela Universidade La Salle. Professora com atuação em salas de recursos \\ multifuncionais. \\ Canoas, Rio Grande do Sul, Brasil. \\ szs.mara@gmail.com
}

\begin{abstract}
Denise Macedo Ziliotto
Pós Doutora em Educação pela Universidade de Lisboa. Professora e pesquisadora do Programa de

Pós Graduação em Educação da Universidade La Salle.

Canoas, Rio Grande do Sul, Brasil.

denise.ziliotto@unilasalle.edu.br
\end{abstract}

\begin{abstract}
Resumo: A pesquisa propõe conhecer as concepções de gestores escolares acerca do processo de inclusão de alunos público-alvo da educação especial no ensino fundamental municipal, identificando experiências atinentes ao tema em análise. $\mathrm{O}$ método é qualitativo, descritivo e de campo, tendo entrevistas como instrumentos de coleta de dados, que foram posteriormente analisadas na perspectiva hermenêutica. A investigação apontou que os gestores concebem a inclusão como um direito do aluno e dever da escola, mas demonstram incertezas em relação à capacidade para garantir a aprendizagem dos estudantes. Com respeito às relações entre direção e comunidade escolar, os gestores buscam parceria das famílias, possuem recursos e apoios para oferecer aos docentes, mas solicitam maior assessoria da Secretaria da Educação e o aumento de quadros técnicos para qualificar a educação oferecida aos alunos.
\end{abstract}

Palavras-chave: Educação especial. Gestão. Inclusão.

\begin{abstract}
The research proposes to know the conceptions of school manager about the process of inclusion of target public students of special education in municipal elementary education, identifying experiences related to the theme under analysis. The method is qualitative, descriptive and field, having as instruments of data collection interviews, which were later analyzed from the hermeneutic perspective. Research has show that managers conceive inclusion as a student's right and school duty, but demonstrate uncertainties about the ability to ensure students learning. With respect to the relations between the school board and the school community, the managers seek family partnerships, have resources and support to offer to teachers, but request greater advice from the education secretariat and the increase of staff to qualify the education offered to students.
\end{abstract}

Keywords: Inclusion. Management. Special Educacion. 


\section{Introdução}

$\mathrm{N}$

a escola, as relações entre os sujeitos devem convergir para um propósito pedagógico: a educação para todos. Para atingir esse objetivo, é preciso que a forma de ser e de fazer no processo educativo esteja intimamente ligada à construção do aprendizado do aluno como ser humano singular. Portanto, a riqueza pedagógica está no se fazer humano na ação (IKESHOJI; TERÇARIOL; RUIZ, 2015). Nessa perspectiva, Vioto e Vitaliano (2012) indicam que o papel do gestor escolar ganha magnitude, pois é ele quem irá conduzir a estrutura organizacional da escola. E uma escola só será inclusiva se o gestor estiver comprometido e disposto a envolver toda a comunidade escolar no fazer inclusivo.

Segundo Lück (2000), Tezani (2004), Mantoan (2003), Carvalho (2005, 2008), Azevedo e Cunha (2008), Dall'Acqua e Vitaliano (2010), Vioto e Vitaliano (2012), Ikeshoji, Terçariol e Ruiz (2015) e Sarmento, Menegat, Seniw(2016), a educação inclusiva implica prover e prever uma escola que possibilite a todos condições de aprendizagem adequadas e de qualidade, respeitando as individualidades e as limitações inerentes a cada sujeito. Os autores também ressaltam a importância da comunidade escolar estar envolvida na construção desse espaço inclusivo. Schmengler e Pavão (2018) assinalam que ao gestor compete estar atualizado e ter conhecimento sobre legislação e direitos dos alunos público-alvo da Educação Especial. Considerando a importância da gestão escolar no que concerne ao processo inclusivo, foi desenvolvida a presente pesquisa que busca assinalar a importância da direção da escola na consecução de uma escola para todos.

O objeto da investigação centra-se na atuação da gestão escolar diante do processo inclusivo de alunos público-alvo da Educação Especial na perspectiva da Educação Inclusiva, identificando concepções e experiências de diretores e vice-diretores. O campo empírico de pesquisa foi a rede municipal de ensino na região metropolitana de Porto Alegre (RS) que - nas últimas décadas, em resposta aos marcos legais em prol dos direitos de acesso e permanência de alunos público-alvo da Educação Especial nas escolas - buscou conferir sustentação às políticas de inclusão existentes. $\mathrm{O}$ método da pesquisa é qualitativo e descritivo, tendo como lócus da investigação quatro escolas da 
rede municipal e como instrumentos de coleta de dados entrevistas com diretores e vice-diretores, posteriormente analisadas na perspectiva hermenêutica.

\section{Ideias balizadoras da educação inclusiva}

A inclusão escolar exige a instalação de uma nova lógica educacional, com a incorporação de projetos pedagógicos contextualizados, valorando a diversidade humana. A proposta inclusiva enseja o rompimento de concepções individualistas, compreendendo as dificuldades específicas dos alunos (OLIVEIRA; DRAGO, 2012). Diante desse novo paradigma que surge na educação, para a escola seguir uma política de Educação Inclusiva, é essencial haver uma adaptação mútua dos alunos e dos espaços, para que os processos inclusivos sejam construídos permitindo que todos possam estar na escola (ROCHA, 2012).

É premente refletir e redimensionar o fazer pedagógico e da gestão escolar na política inclusiva. A capacitação profissional, o comprometimento de todos os envolvidos no processo educacional e as adaptações/adequações no ambiente escolar, são elementos que viabilizarão a prática inclusiva de qualidade (FREITAS; TEIXEIRA; RECH, 2016). Uma educação inclusiva procura atender às necessidades de todos os indivíduos que a frequentam, possibilitando a participação em todas as atividades escolares de forma que se sintam acolhidos no ambiente escolar. O processo inclusivo impõe mudanças significativas no modo de pensar e projetar o papel da escola, e no desenvolvimento de ações pedagógicas eficazes que contemplem o aprendizado de todos os alunos (NUNES; MADUREIRA, 2015).

O processo de inserção para alunos público-alvo da Educação Especial no ensino fundamental do ensino regular requer de toda a equipe escolar respostas que atendam às exigências desses alunos em suas particularidades e vivências. Para tanto, exige que a gestão esteja voltada às demandas educacionais e que o professor tenha competência pedagógica para oferecer atendimento a todos os alunos com suas diferenças. O que está prescrito em decretos, portarias ou leis, uma vez que traça metas, planifica, gerencia e possibilita a concretização das proposições e anseios na direção de uma escola inclusiva, aciona decisões políticas de melhorias educacionais conduzindo a construção de uma escola democrática e emancipadora. No entanto, é preciso clarificar que, por si só, as leis não 
estabelecem espaços inclusivos. As leis os possibilitam, mas os profissionais da educação, ao respeitarem as diferenças, colocando a diversidade como fator preponderante na apropriação de conhecimentos humanizados, é que são os protagonistas desta construção juntamente com os alunos (OLIVEIRA; DRAGO, 2012). Cabe à educação beneficiar todos os que dela necessitam com sistemas educacionais inclusivos, capazes de adequar-se às diferenças, sempre estimulando a autonomia e a criatividade do aluno (FARIAS, CUNHA e PINTO, 2016).

A Educação Inclusiva vem se consolidando com uma série de preceitos legais que, gradativamente, têm transformado a organização das escolas. Entretanto, conforme aponta Estef (2016), a Educação Inclusiva não está fundamentada apenas na garantia de acesso e permanência de alunos público-alvo da Educação Especial no ensino regular. O processo de inclusão precisa propiciar ao aluno a permanência com a garantia do desenvolvimento de suas potencialidades na apropriação de novos aprendizados, respeitando suas particularidades. Para que seja possível atender às necessidades dos alunos, construindo bases pedagógicas de modo a garantir o aprendizado, faz-se necessária, segundo a autora, a promoção de diálogos reflexivos entre os múltiplos atores que compõem o cenário escolar.

Oliveira e Leite (2007), Azevedo e Cunha (2008), assim como Boaventura (2008), assinalam a importância do convívio de respeito à diversidade, evidenciando a necessidade constante de aprimoramento nas metodologias e intervenções para que adaptações pedagógicas competentes se façam presentes no cotidiano escolar. Os autores também acentuam a importância do sujeito públicoalvo da Educação Especial exercitar a cidadania de forma ativa em seu ambiente social. Oliveira e Drago (2012), assim como Farias, Cunha e Pinto (2016) destacam que a escola inclusiva é construída no coletivo, com o engajamento de toda a equipe escolar estabelecendo diferentes abordagens de ensino para responder às necessidades de aprendizagem de seus alunos. Os autores evidenciam que as leis possibilitam a criação de espaços inclusivos, mas os profissionais da educação precisam estabelecê-los, enquanto articuladores e mediadores na efetivação da aprendizagem de seus alunos.

\section{Gestão escolar e inclusão}


Um projeto de educação inclusiva só é desenvolvido com uma gestão que engendra o envolvimento organizado de toda a escola na conquista da educação de qualidade para todos (TEZANI, 2004). Freitas (2014) notabiliza a importância do clima e da cultura organizacional participativa de uma gestão democrática, na qual o sentimento de pertencimento surja da participação e do apoio da comunidade nas mudanças que o processo inclusivo requer. E esse processo inclusivo - enfatizam Deimling e Moscardini (2017) - deve estar alicerçado numa proposta pedagógica rica em estímulos de aprendizagem, segundo a qual cada um possa ser compreendido como sujeito único, que traz em si potencial de desenvolvimento cognitivo e humano.

Considerando os desafios pertinentes ao processo inclusivo que, segundo Oliveira e Drago (2012), exigem dos gestores o estabelecimento de uma nova lógica educacional, no planejamento de projetos pedagógicos afinados com a comunidade escolar, há também a necessidade de romper com o estigma de vincular deficiência com incapacidade, ou seja, superar velhos paradigmas compreendendo e respeitando as diferenças. No entanto, Castro, Amaral e Borges (2017), declaram ainda haver uma lacuna entre a legislação existente e as práticas sociais em relação à deficiência, pois ainda prevalece a ideia de desqualificação e de patologia. Para Wellichan e Souza (2017), é essencial refletir sobre a prática pedagógica e administrativa na política inclusiva, pois, somente com o comprometimento de todos, a inclusão se efetivará de fato.

Para lidar com essas dimensões políticas, administrativas e pedagógicas a fim de efetivar a escola inclusiva, o processo de formação continuada para gestores e professores deve ser ininterrupto e contextualizado (MICHELS, 2006). Além disso, a participação dos professores na elaboração do Projeto Político Pedagógico fortalece o comprometimento dos envolvidos com a execução das diretrizes e resoluções, de maneira satisfatória (REGO, 2016).

Vale ressaltar que à gestão escolar, no que diz respeito à inclusão, compete ter uma intenção explícita, com foco na organização e orientação do trabalho pedagógico, sendo esse aspecto basilar para o avanço da escola. E imprescindível que a direção, ao pactuar com a educação inclusiva, despreze modelos de gestão que transformam a escola em espaço de poder, não permitindo a participação dos atores envolvidos no destino da instituição (SILVEIRA, 2009). Para obter êxito no processo escolar inclusivo, Boaes (2015) assinala que a gestão democrática e participativa é o caminho, pois na medida que todos se comprometem com o processo educativo, o desempenho dos alunos é contemplado de 
forma singular. Lima (2016) argumenta que a autonomia é fator preeminente na articulação entre gestão escolar e inclusão, para a viabilização das condições de trabalho. A autora sublinha a interdependência existente entre educação inclusiva e gestão escolar em alinhamento com a gestão democrática participativa para a supressão de qualquer forma de exclusão, estabelecendo-se o diálogo entre os partícipes do processo.

\section{Método}

Para a realização desta investigação, que se centra nas concepções de gestores escolares acerca da inclusão, optou-se pela modalidade qualitativa que, segundo Minayo (2010), dedica-se às questões singulares. Essa modalidade de pesquisa se desenvolve no universo das relações dos processos com as crenças, valores, aspirações e significados pertinentes ao contexto histórico e social, que perdem a significância quando tratados quantitativamente. Já o delineamento descritivo justifica-se pela necessidade de descrever e interpretar o objeto em estudo, sendo utilizado para identificar, registrar e analisar as variáveis que se inter-relacionam com o objeto pesquisado, sem interferir na realidade estudada, mas, sim, conhecer e interpretar (BARROS; LEHFELD, 2007).

A investigação foi realizada em quatro escolas de ensino fundamental da rede municipal em cidade na região metropolitana de Porto Alegre (RS), representando os quadrantes sudoeste, noroeste, nordeste e sudoeste, sendo sujeitos participantes da investigação os diretores e vice-diretores das escolas. A indicação das escolas ocorreu após trâmites na secretaria Municipal de Educação (SME) para ciência e autorização da realização da pesquisa, havendo posterior contato e concordância dos diretores das escolas. Os instrumentos de coleta de dados da pesquisa foram entrevistas com os diretores. Os participantes da pesquisa - diretores e vice-diretores das escolas - foram convidados e, mediante a assinatura do Termo de Consentimento Livre e Esclarecido, foram entrevistados em dupla, conforme escolha dos participantes, a partir de roteiro semiestruturado, sendo posteriormente transcritas as contribuições. A modalidade analítica hermenêutica foi empregada para tratamento dos 
elementos advindos da coleta de dados, dialogando com as fontes de pesquisa, segundo as postulações de Flickinger e Rohden (2000).

\section{Análise e apresentação dos dados}

As quatro escolas (E1, E2, E3 e E4) possuem instalações que compreendem cozinha, biblioteca, banheiro para professores, banheiros com acessibilidade para alunos, praça, quadra de esportes coberta, sala de direção, sala de professores, sala do setor pedagógico e sala de recursos multifuncionais com recursos pedagógicos. No que concerne à acessibilidade, as escolas possuem rampas de acesso às áreas de uso comum, como refeitório, biblioteca, laboratório, sala de recursos multifuncional (SEM) e banheiros adaptados. Em relação à acessibilidade, A E1 necessita de passarela de acesso para quadra de esportes e praça, pois o pátio é coberto com brita. A E2 é uma escola grande; tem dois pisos, mas apresenta excelente acessibilidade e ambientes adaptados. O prédio da E3 também tem dois pisos - e, embora a escola apresente alguns desníveis no pátio - há acesso por meio de rampas para vários locais. A E4, embora apresente rampas de acesso para todos os locais de uso comum, é assentada em um terreno que apresenta muitos desníveis, necessitando ainda maior investimento em termos de acessibilidade, como corrimões para alunos com maiores dificuldades de locomoção.

As quatro escolas contam com SRM equipadas com material pedagógico diversificado recebido do MEC e coma atuação de profissionais especializados no AEE com carga horária de 40 horas semanais. As escolas oferecem aos alunos público-alvo da Educação Especial incluídos no Ensino Fundamental o atendimento educacional especializado (AEE) no turno inverso à aula regular. Os técnicos de educação básica (TEB) que exercem atividades de apoio à docência no ensino fundamental aos alunos público-alvo da EE atuam nas quatro escolas com 40 horas semanais, e há estagiários cursando nível superior que desenvolvem atividades de apoio aos alunos de inclusão nas escolas.

Os participantes desta pesquisa são diretores e vice-diretores das escolas indicadas pela SME, cujas atribuições estão descritas pela Lei Municipal. A direção escolar é responsável pela coordenação - em consonância com o Conselho Escolar - elaboração, execução e avaliação do projeto 
administrativo financeiro e pedagógico da escola, observando as políticas públicas da SME e corroborando para a melhoria do trabalho docente e a promoção permanente da aprendizagem do aluno. Cabe à vice-direção participar da administração da instituição escolar em regime de colaboração com o diretor e substituí-lo legalmente em seus impedimentos.

Das quatro escolas entrevistadas, somente a Escola 2 e a Escola 4 têm vice-direção, já que é exigido número superior a 500 alunos para esse cargo ser ocupado. Ao realizar a entrevista nas escolas que possuem mais de 500 alunos, a direção e a vice-direção optaram por realizar conjuntamente o contato com a pesquisadora. $\mathrm{Na}$ Erro! Fonte de referência não encontrada., são apresentados os diretores e vice-diretores das quatro escolas em estudo.

Tabela 1 - Diretores e vice-diretores das escolas pesquisadas

\begin{tabular}{|c|c|c|c|c|}
\hline Participantes & Idade/Sexo & $\begin{array}{c}\text { Atuação Ensino Muni- } \\
\text { cipal/anos }\end{array}$ & Atuação escola/ anos & $\begin{array}{c}\text { Atuação função dire- } \\
\text { tiva }\end{array}$ \\
\hline Escola 1 & $\mathrm{D}-37 / \mathrm{M}$ & D - 09 & D - 09 & D - 03 \\
\hline \multirow{2}{*}{ Escola 2} & $\mathrm{D}-58 / \mathrm{F}$ & $\mathrm{D}-37$ & $\mathrm{D}-37$ & D - 07 \\
\hline & $\mathrm{VD}-48 / \mathrm{F}$ & VD - 27 & VD - 27 & $\mathrm{VD}-10$ \\
\hline Escola 3 & $\mathrm{D}-55 / \mathrm{F}$ & D - 20 & D - 18 & D - 08 \\
\hline \multirow{2}{*}{ Escola 4} & $\mathrm{D}-47 / \mathrm{F}$ & $\mathrm{D}-23$ & $\mathrm{D}-21$ & D - 10 meses \\
\hline & $\mathrm{VD}-40 / \mathrm{F}$ & VD - 22 & VD - 09 & VD -10 meses \\
\hline
\end{tabular}

Fonte: Elaborado pelas autoras

Das quatro escolas onde a pesquisa foi realizada, somente há um diretor (E1), sendo as demais participantes mulheres. Quanto ao tempo de atuação na Educação, tanto no magistério municipal quanto na escola, a média é de 20 anos, o que indica uma trajetória profissional significativa, pressupondo conhecimento não só sobre a comunidade escolar, mas também sobre o público atendido. A participante com maior permanência na direção é a da E2, que soma 10 anos na vice- 
direção. Na E4 - após período eleitoral em 2017, em todas as escolas da rede municipal - houve constituição de nova direção, e as profissionais estão na escola há 21 anos e 09 anos.

Quanto à formação do diretor e das diretoras das escolas, o diretor da E1 e a diretora da E3 têm especialização em Educação Inclusiva, o que sugere conhecimento sobre o processo inclusivo. $\mathrm{Na}$ E2, a diretora tem Especialização na Educação de Jovens e Adultos e, sendo pedagoga, atuou, por 20 anos, como supervisora da escola. A vice-diretora da E2 tem especialização em Psicopedagogia e, desde que assumiu no município, trabalhou no atendimento a alunos da Educação Especial. A diretora da E4, enquanto pedagoga, atuou na escola como orientadora educacional, e a vice-diretora possui especialização em Psicomotricidade Relacional, tendo anteriormente atuado no acompanhamento individualizado ou em grupos de alunos público-alvo da escola. Portanto, a formação e a percurso profissional dos diretores e vice-diretores das quatro escolas sugere proximidade e conhecimento não somente sobre a inclusão como também sobre a proposta educacional inclusiva.

A seguir, são analisados aspectos atinentes à gestão nas escolas pesquisadas, a partir das dimensões - concepções sobre a inclusão, relação com famílias e incertezas e impotências na experiência da inclusão-que emergiram nas entrevistas, explicitando as questões que elucidam os objetivos da investigação realizada.

Os gestores participantes dessa pesquisa, que vivenciam o cotidiano escolar em diferentes contextos, compartilharam entendimento sobre o processo de inclusão que a escola vivencia. D1 avalia que "o processo de inclusão veio a agregar valor à educação nos últimos tempos. Trouxe, para a escola e para o convivio social, muitas crianças que antes ficavam no anonimato, em suas casas, sem convivio com seus pares e sem desafios cognitivos". D2 dimensiona a inclusão como “um processo mais amplo, que envolve a todos no ambiente escolar, mas que vai além dos muros da escola [...] Sabemos que é uma inclusão. Mas quais serão os desafios que iremos enfrentar, não. Cabe a nós acolhermos, conhecermos, interagirmos e trabalharmos".

D3 explicita a realidade que todas as escolas atualmente são inclusivas perante a lei, pois garantem a matrícula de alunos público-alvo EE. Contudo, reflete que "isso não torna uma escola inclusiva. O processo inclusivo exige comprometimento, envolvimento, estudo, atualização de toda a equipe escolar. As ações precisam ser pensadas coletivamente e todos devem estar envolvidos. Consideramos, sim, nossa escola inclusiva pelo acolbimento e pelo trabalho que desenvolvemos". D4 identifica fatores relacionados à inclusão, pois, “com o 
tempo temos percebido que variáveis como aluno e família irão faz̧er grande diferença de como será traçado esse percurso". VD4 complementa afirmando que

Enquanto gestores, temos que estar atentos a tudo: à atuação dos professores, dos pais, dos colegas e de que forma estamos trabalhando e como nossa ação tem dado sustentação à promoção de ações pedagógicas diferenciadas que possibilitam um ambiente escolar onde todos possam aprender.

D1 entende que " todas as ações, sejam pedagógicas sejam administrativas, sempre têm que pensar na inclusão. As ações que vamos desenvolver têm que contemplar a todos, seja no espaço físico, em termos de acessibilidade, seja em recursos pedagógicos, assim como em recursos humanos". D2 e a VD2 ainda enfatizam o compromisso e a responsabilidade de acompanhar e primar pela documentação da vida escolar dos alunos. De acordo com Vioto e Vitaliano (2012), organizar uma escola inclusiva não é tarefa cômoda e fácil: o gestor precisa ter clareza da representatividade e influência da sua função na organização escolar para tornar a escola inclusiva. Os autores acentuam que as mudanças necessárias muitas vezes colocam em choque questões conceituais ligadas à diferença.

Em relação às concepções e posicionamentos dos participantes enquanto gestores, há o reconhecimento do contingente de alunos que hoje integra a escola regular não se reduzir àqueles cujo diagnóstico identifica somente as necessidades de aprendizagem. No entanto, não dimensionam este contexto numa perspectiva histórica ou mesmo avaliam a inclusão numa dimensão mais ampla que sua escola, mas concebem a comunidade e as famílias como fundamentais neste processo. $\mathrm{O}$ acolhimento foi assinalado nas entrevistas como uma ação importante neste âmbito, o que talvez circunscreva, em nível ainda não pedagógico, a entrada do aluno na escola, situando como a inclusão é ainda um processo em construção mesmo na educação. As menções dos participantes transparecem uma implicação dos gestores com a inclusão, mesmo que, nas ações administrativas e legais (documentação), o que sinaliza possivelmente sua ciência e envolvimento imbricados, diante dessas questões que a escola precisa responder enquanto agente público.

Ao considerar a comunidade escolar, os gestores apontam a importância da participação dos pais ou responsáveis na escolarização dos alunos público-alvo da EE, para que a inclusão possa se efetivar. D2 refere que " a sociedade ainda tem dúvidas a respeito. Mas hoje a comunidade aceita os alunos inclusos". VD2 lembra que "Houve momentos em que fomos questionadas se o aluno incluso iria ficar na turma do seu filho. 
Sabe-se que todos os pais, na escola, precisam ser trabalhados. No entanto, nossa comunidade participa pouco das reuniōes escolares". D3 afirma que "a comunidade nunca repeliu ou demonstrou contrariedade em relação aos alunos de inclusão em nossa escola. Com os alunos, é gratificante de se ver a naturalidade e respeito com que eles tratam os colegas. São receptivos, acolhedores, cuidadores, e isso é uma cultura que há neles”.

VD2 considera que "Apesar do tempo em que estamos na escola, em muitos momentos nos sentimos sem poder de ação, principalmente no que se refere aos recursos humanos necessários para os atendimentos em sala de aula". D3 avalia que "Na realidade, com o processo de inclusão, nem sempre sentimos que correspondemos, enquanto escola, às necessidades de todos os alunos com deficiência". D4 afirma: "quando não se consegue avançar com o caso de um aluno, vem a frustração". Os participantes manifestaram dúvidas sobre a permanência de alguns alunos de inclusão na escola por não perceberem evolução no aprendizado destes.

Para a concretização da inclusão, D1 menciona a necessidade de infraestrutura, verba para materiais pedagógicos e recursos humanos, tendo a "meta de tentar um estagiário como resposta à família e apoio também ao professor que com 30 alunos". D3 aponta a necessidade de maior apoio da secretaria municipal da educação, por meio da presença mais efetiva nas escolas, a fim de acompanhar o trabalho realizado.

A construção da escola inclusiva é contextualizada por D1: "Hoje mais pessoas conseguem entender o que é inclusão, mas ainda temos que evoluir no desenvolvimento de metodologias e no entendimento do sujeito que aprende", dimensionando o quanto o processo se encontra em desenvolvimento e o quanto os gestores são fundamentais nesta trajetória.

\section{Considerações finais}

Os diretores evidenciam concepções pedagógicas inclusivas ao acentuarem que a inclusão traz desafios e aprendizados, mas exige conhecimento. Os diretores entendem que a inclusão enseja inovações e aprendizado no processo pedagógico, pois o ingresso dos alunos público-alvo da Educação Especial é uma experiência que vem sendo construída pela escola e pela comunidade. Fazem-se necessárias reflexões e ações para que os alunos permaneçam e sejam instrumentalizados 
por meio do conhecimento. Assim, a formação continuada, o estudo, a pesquisa e a atualização constante passam a ser exigências para poder atender à demanda que se apresenta.

Entre os processos implicados na inclusão, os gestores entrevistados mencionaram a preocupação com a falta de recursos humanos, especialmente os profissionais de apoio para os alunos que precisam de acompanhamento. Em relação às famílias, os diretores enfatizam a importância do acolhimento pela escola, buscando estabelecer uma relação de confiança e cooperação, para que estejam presentes na vida escolar dos alunos. As direções também declaram que evidenciam maior aceitação da comunidade escolar em relação aos alunos incluídos, mas que ainda se faz necessário um trabalho mais efetivo para que se construa um maior conhecimento sobre a inclusão.

\section{Referências}

AZEVEDO, M. A. R.; CUNHA, G. R. Gestão Escolar e Educação Inclusiva: uma parceria necessária e emergente na escola. Educação: teoria e prática, v.18, n. 31, p 53- 72, jul-dez, 2008.

BARROS, A. J. S.; LEHFELD, N. A. S. Fundamentos de metodologia cientifica. 3. ed. Pearson Prentice Hall, São Paulo, 2007.

BOAES, K.F. Mecanismos de Construção da Gestão Democrática: um estudo em três escolas municipais da cidade de São Luís - V Seminário Internacional sobre Profissionalização Docente. São Luís/MA.

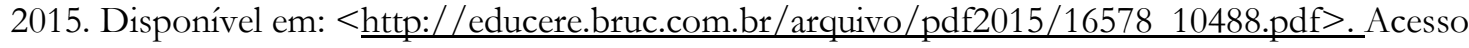
em: 05 mar. 2017.

BOAVENTURA, R. S. A Gestão Escolar na Perspectiva da Inclusão. 2008. 123f. Dissertação (Mestrado em Educação). Universidade do Oeste Paulista. Presidente Prudente, São Paulo, 2008. Disponível 
em: http://bdtd.unoeste.br:8080/jspui/bitstream/tede/760/1/dissertacao\%20Roberta.pdf. Acesso em: 15 out. 2018 .

CARVALHO, R.E. Educação inclusiva: com os pingos nos “is”. Porto Alegre: Mediação, 2005.

CARVALHO, R.E. Escola e reorganização do trabalho pedagógico. Porto Alegre: Mediação, 2008.

DALL'ACQUA, M. J. C.; VITALIANO, C. R. Algumas reflexões sobre o processo de inclusão em nosso contexto educacional. In: VITALIANO (org.). Formação de professores para a inclusão de alunos com necessidades educacionais especiais. EDUEL, Londrina, 2010.

DEIMLING, N. N.M.; MOSCARDINI, S. F. Inclusão Escolar: Política, Marcos Históricos, Avanços e Desafios. Revista online de Política de Gestão Educacional, v.21, n.1, jan-abr., 2017. Disponível em: <seer.fclar.unesp.br/rpge/article/download/9325/6177>.Acesso em: out. 2017.

ESTEF, S. Concepç̃es sobre o processo de avaliação escolar para alunos com necessidades educacionais especiais sob a ótica docente. Dissertação de Mestrado. Universidade do Rio de Janeiro - UERJ - RJ. Rio de Janeiro, 2016.

FARIAS, C. C.; CUNHA, R. S.; PINTO, R. B. Estatuto da pessoa com deficiência comentado. 2. ed. rev. Juspodium, Salvador, 2016.

FLICKINGER, H. G.; ROHDEN, L. Hermenêutica filosófica: nas trilhas de Hans-Georg Gadamer. EDIPUCRS, Porto Alegre. 2000.

FREITAS, F. P. M. Gestão e Inclusão Escolar: A Formação do Gestor Escolar No Programa "Educação Inclusiva: Direito a Diversidade" (2003 - 2013). Dissertação de Mestrado. Universidade Estadual do Centro Oeste - UNICENTRO. Guarapuava, 2014.

FREITAS, S. N.; TEIXEIRA, C. T.; RECH, A. J. D. Alunos com deficiência em situação de acolhimento institucional: desafios para a gestão e a inclusão escolar. RLAEE - Revista IberoAmericana de Estudos em Educação, v. 11, n. 4, p.2104-2124, 2016. Disponível 
em: $\leq$ http://seer.fclar.unesp.br/iberoamericana/article/view/8214/6048>. Acesso em: 29 abr. 2017.

IKESHOJI, E. A. B.; TERÇARIOL, A. A. L.; RUIZ, A. R. A gestão escolar em foco: Reflexões preliminares. ColloquiumHumanarum, Presidente Prudente, v. 12, n. 2, p.11-18, abr/jun 2015.

LIMA, E. C. V. Gestão Escolar e Politica Educacional de Inclusão na rede de Ensino Municipal de Manaus: Uma Reflexão à luz da Teoria Crítica. Dissertação de Mestrado. Universidade Federal do Amazonas, Manaus. 2016.

MANTOAN, M.T. E. Inclusão Escolar: o que é? Por quê? Como fazer? São Paulo. Moderna, 2003.

MINAYO, M. C. S. (org.). Pesquisa social: teoria, método e criatividade. 29. ed., Vozes, RJ, 2010.

NUNES, C.; MADUREIRA, I. Desenho Universal para a Aprendizagem: Construindo práticas pedagógicas inclusivas. Invest. Práticas, v. 5, n. 2, p. 126-143, 2015. Disponível em:

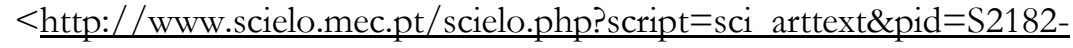
13722015000200008\&lng=pt\&nrm=iso >. Acesso: 13 mai. 2017.OLIVEIRA, A. A. S.;

DRAGO, S. L. S. A gestão da inclusão escolar na rede municipal de São Paulo: algumas considerações sobre o Programa Inclui. Ensaio: avaliação de políticas públicas educacionais [online].v. 20, $\mathrm{n}$. 75, p. 347-372, abr./jun. Rio de Janeiro, 2012

OLIVEIRA, A. A. S.; LEITE, L. P. Construção de um Sistema Educacional Inclusivo: um desafio político-pedagógico. Ensaio: Avaliação e Políticas Públicas em Educação. v.15, p. 511-524, 2007.

REGO, A. F. F. Gestão escolar e inclusão digital: uso da tecnologia digital como recurso didático na escola Estelita Timóteo. Dissertação de Mestrado. Universidade Federal da Paraíba, João Pessoa, 2016.

ROCHA, S. M. P.S.. Gestão e organização da escola para a inclusão: o acompanhamento como fator de mudanças. $35^{a}$ reunião da ANPED. 2012. Disponível em:

< http://35reuniao.anped.org.br/images/stories/trabalhos/GT15\%20Trabalhos/GT15-2057 int.pdf $>$.Acesso em: 16 ago. 2017.Disponível em:

SARMENTO, D. F., MENEGAT, J. SENIW, R. M. Qualidade educacional e gestão. Formação, investigação e práticas gestoras. Revista Ibero-Americana de Estudos em Educação, v. 70, p. 55-76, 2016. Disponível em: < https://rieoei.org/historico/documentos/rie70a03.pdf>. Acesso em: 02 mar. 2017.

SILVA, C. L. LEME, M. I. S.. O papel do diretor escolar na implantação de uma cultura educacional inclusiva. Psicol. cienc. prof., Brasília, v. 29,n. 3,p. 494-511, 2009. Disponível 
em:<http://www.scielo.br/scielo.php?script=sci_arttext\&pid=S1414-

98932009000300006\&lng=pt\&nrm=iso > Acesso em 06 maio 2017.

SILVEIRA, S. M. P. A Gestão para a Inclusão: Uma Pesquisa Ação Colaborativa no Meio Escolar. 2009. 223f. Tese (Doutorado em Educação). Universidade Federal do Ceará. Fortaleza, 2009. Disponível em: <http://www.repositorio.ufc.br/ bitstream/riufc/6642/1/2009_tese_smpsilveira.pdf>. Acesso em: 15 out. 2017.

TEZANI, T. C. R. Os caminhos para construção da escola inclusiva: a relação entre a gestão escolar e o processo de inclusão. 2004, 221f. Dissertação (Mestrado em Ciências Humanas). Universidade Federal de São Carlos, São Carlos, 2004. Disponível em:

$<$ https://repositorio.ufscar.br/handle/ufscar/2638?show=full $>$. Acesso em: 12 out. 2017.

VELLOSA, S. R. C. L. MANZOLI, L. P. As Tendências Educacionais Politizadoras do Processo Inclusivo: acertos e desacertos. Revista online de Política e Gestão Educacional, n. 6, 2009. DOI: https://doi.org/10.22633/rpge.v0i6.9250. Disponível em: <https://periodicos.fclar.unesp.br/rpge/article/view/9250> Acesso em: 14 dez. 2018.

VIOTO, J. R. B., VITALIANO, C. R. O papel da gestão pedagógica frente ao processo de inclusão dos alunos com necessidades educacionais especiais. Seminário de Pesquisa em educação da Região Sul - IX ANPED SUL. 2012. Disponível em:

$<$ http://www.ucs.br/etc/conferencias/index.php/anpedsul/9anpedsul/paper/viewFile/660/668>. Acesso em: 02 out. 2017.

WELLICHAN, D. S. P. SOUZA, C. S.A inclusão na prática: alunos com deficiência no ensino superior. Revista online de Política e Gestão Educacional, v.21, n.1, p. 146-166, 2017. Disponível em:

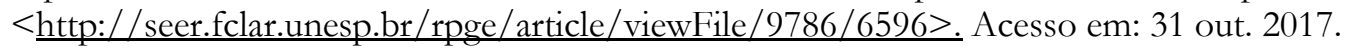

Recebido em 20 fev. 2019 / Aprovado em 31 out. 2019

\section{Para referenciar este texto:}

SOARES, Mara Rosane Souza; ZILIOTTO, Denise Macedo; O gestor escolar e a inclusão de alunos público-alvo da educação especial. Cadernos de Pós-graduacão, São Paulo, v. 18, n. 2, p. 220-234, jul./dez. 2019. Disponível em: < <https://doi.org/10.5585/cpg.v18n2.13150>. 